\title{
Qualitative Research Informing a Preference Study on Selecting Cannabis for Cancer Survivor Symptom Management: Design of a Discrete Choice Experiment
}

\author{
Colene Bentley ${ }^{1,2}$ (D) Sara Izadi-Najafabadi ${ }^{1,2}$ (D) Adam Raymakers ${ }^{1,2,3}$ ([) $\cdot$ Helen McTaggart-Cowan ${ }^{1,2,3}$ (D)
}

Accepted: 13 December 2021 / Published online: 8 February 2022

(c) The Author(s) 2022

\begin{abstract}
Introduction The legalization of recreational cannabis use can enable cancer survivors to manage aspects of their care with cannabinoids without medical authorization or stigmatization. However, the absence of medical guidance-from the scientific literature or the healthcare system-makes it difficult for survivors to reach informed decisions about their care. Objective This article outlines the qualitative research undertaken to design a discrete choice experiment (DCE) aimed at understanding Canadian cancer survivors' preferences for managing their cancer symptoms with cannabis in this complex socio-medical context.

Methods In this study, we drew on previously published qualitative research (a literature review and interviews with cancer survivors) and the theory of planned behavior, holding weekly team meetings to review the qualitative data and identify initial attributes associated with medicinal cannabis consumption to inform the DCE design. The initial attributes were further assessed to determine whether they were sensitive to the Canadian context, modifiable to produce levels and trade-offs, and amenable to policy intervention, in order to form the DCE choice sets. The choice sets were tested via think-aloud exercises with members of the general population and included debriefing interviews. Think-aloud participants were recruited from patient groups and previous studies. Results Based on our review of the interview study, we identified the following attributes associated with selecting medicinal cannabis: effectiveness; chance of side effects; support from family, friends, and/or physicians; cost; and availability. Ability to perform everyday activities was added and monthly out-of-pocket cost was refined to render the DCE realistic to cancer survivors in the Canadian context. Revisions to the DCE instructions, terminology, and cost levels were made based on results from the think-aloud exercises $(n=10)$.

Conclusions This qualitative study outlines the preference evidence collected regarding Canadian cancer survivors' decisions to manage their symptoms with cannabis to inform a DCE quantitative survey. It contributes to transparent reporting of qualitative work in DCE development and to understanding cancer survivors' preferences regarding medicinal cannabis consumption under legalization.
\end{abstract}

\section{Introduction}

In October 2018, the Cannabis Act legalized the recreational consumption of cannabis in Canada [1]. Canadian adults (aged $\geq 18$ years) can now legally access cannabis and

Colene Bentley

cbentley@bccrc.ca

1 Cancer Control Research, BC Cancer Research Institute, 675 West 10th Avenue, Vancouver, BC V5Z 1L3, Canada

2 Canadian Centre for Applied Research in Cancer Control, Vancouver, BC, Canada

3 Faculty of Health Sciences, Simon Fraser University, Burnaby, BC, Canada cannabis-derived products such as edibles and oils through regulated dispensaries and can grow up to four cannabis plants at home for personal use. For individuals wanting to consume cannabis for therapeutic purposes-such as cancer survivors and those with chronic conditions - the passing of the Cannabis Act meant they no longer needed medical documentation to do so.

Consumption of medicinal cannabis without medical guidance exacerbates an existing healthcare issue in Canada and elsewhere; namely, there is little clinical evidence on how well it works [2,3]. Specifically, a robust evidence base on the therapeutic effects of cannabis (e.g., dosage, drug interactions, product type, side effects) is lacking to support physicians prescribing these products $[1,2,4,5]$ and — post 


\section{Key Points for Decision Makers}

This article describes a qualitative research approach to developing a preference survey aimed at understanding Canadian cancer survivors' decisions to manage their symptoms with cannabis in the context of legalized cannabis consumption.

Qualitative research is foundational to achieving a discrete choice experiment (DCE) design that is meaningful to patients and stakeholders, context sensitive, and amenable to policy formation.

Our findings showed that cannabis was widely believed to have therapeutic effects. However, the stigma often associated with cannabis use in social and healthcare contexts left some survivors without medical guidance to support their decisions regarding cannabis consumption and symptom relief.

In jurisdictions such as Canada, where recreational cannabis consumption was recently legalized, this information can be used to support person-centered care and shared decision making between patients and physicians in oncology and health policy.

legalization in Canada - to inform a growing number of consumers $[6,7]$. Moreover, the social stigma often associated with cannabis use may dissuade patients and recreational users alike from disclosing their use to their physician, family, and friends [8-10]. Access to cannabis without medical authorization may enable patients to self-direct aspects of their care, but it disrupts the principles of person-centered care when cannabis-related knowledge is missing from shared decision making between patients and their doctors.

Few high-quality clinical trials exist on cannabis use in oncology $[2,11]$. However, two recent reviews of the health effects of cannabis and cannabinoids found evidence of its effectiveness in treating chemotherapy-induced nausea and vomiting, insomnia, and cancer-associated chronic and neuropathic pain in survivors $[2,12]$. Because cancer survivors-defined as individuals diagnosed with cancer until the end of their lives [13] — may experience these symptoms during and long after undergoing active treatment, medicinal cannabis can help lessen cancer's prolonged impact on their lives. Less restricted access to cannabis through its legalization can empower cancer survivors and others to manage their own wellbeing, potentially outside the conventional healthcare system.

This article describes an approach to understanding Canadian cancer survivors' decisions to manage their symptoms with cannabis in this complex socio-medical context. Specifically, it describes the formative qualitative research undertaken to support the design of a discrete choice experiment (DCE) survey on individuals' preferences regarding medicinal cannabis use. DCE surveys are used to assess stakeholders' preferences related to a healthcare service or intervention [14-16]. A DCE approach to preference elicitation involves describing the healthcare service or intervention by its features or "attributes," which can be decomposed into specific levels $[14,15]$. Survey participants indicate the relative value they place on these attributes through their response to a series of choice sets, with attribute levels varying across the choice sets. For our purposes, a DCE survey would provide evidence on what attributes affect individuals' decisions to consume cannabis for therapeutic purposes in an effort to support person-centered care and shared decision making in oncology and Canadian health policy.

Qualitative research is foundational to developing DCE attributes that are meaningful to patients and policymakers, realistic, capable of being traded, and amenable to policy formation [17-21]. This article reports on the qualitative research undertaken to generate attributes and levels for a DCE designed to collect policy-relevant evidence on cancer survivors' preferences for taking (or not taking) cannabis for symptom management.

The qualitative research reported here includes (1) identification of preliminary attributes to inform the initial DCE instrument, based on our previous qualitative work (a literature review and interview study with Canadian cancer survivors) [10]; (2) the refinement of attributes and levels for inclusion in the pilot DCE design; and (3) assessing the comprehension and acceptability of the DCE design based on results from think-aloud exercises with debriefing interviews. This approach helps establish the content validity of the DCE instrument $[18,22,23]$ and provides a realistic evidence base on cancer survivorship and medicinal cannabis consumption to help inform Canadian health policy. We use "medicinal cannabis" throughout to denote cannabisderived products consumed for therapeutic purposes. The study protocol was approved by the BC Cancer Research Ethics Board (H19-01489).

\section{Methods}

Following guidelines on reporting formative qualitative research for instrument development [18], we provide a rationale for the theoretical approach and study design undertaken in developing the DCE survey. The multidisciplinary research team-comprising health economists with practical and theoretical background in DCE development and working in the field of cancer survivorship, senior qualitative researchers, and an oncologist supporting 
cancer survivors with medical cannabis-had input on the study design. The team met weekly throughout the qualitative research process to discuss the development and implementation of the methods and the interpretation of results. Any disagreements were resolved through discussion and consensus.

The theory of planned behavior (TPB) provided the theoretical framework for the qualitative work. The TPB is a well-validated, psychological, and theoretically structured framework for assessing intentions, which are deemed strong predictors of behavior [24, 25]. The TPB posits that an individual's intention to act is determined by three components or conceptual constructs: attitudes (i.e., an individual's favorable/unfavorable assessment of performing a particular behavior), subjective norms (i.e., the perceived social pressure to perform/not perform the behavior), and perceived behavior control (i.e., the perceived ease/difficulty of performing the behavior) [24, 25]. Specific antecedent beliefs underlie each of the constructs: behavioral beliefs (regarding the consequences of performing the action), normative beliefs (about perceived social pressure or support in performing the action), and control beliefs (regarding factors that facilitate or hinder the activity under consideration). By linking complex intentions and behavior, the TPB can help predict the uptake (i.e., the behavior of interest) of a good or service. It thus offers a complementary framework to DCEs in identifying and assessing individuals' relative desire for a particular good or service.

The development of the DCE entailed a three-stage approach, with each stage informing the next. The stages were (1) identifying a long list of initial attributes based on previous qualitative work (a literature search and interviews with cancer survivors); (2) reducing the list of initial attributes and levels to a number appropriate for inclusion in a DCE choice set; and (3) conducting think-aloud exercises with debriefing interviews to further refine the DCE design for comprehensibility and acceptability.

Our previous qualitative work was conducted in 2019. It involved a literature search and interview study with cancer survivors to understand the factors that affected their decision to consume (or not) cannabis to manage their cancer symptoms. Findings from the literature search were mapped onto the TPB constructs (Fig. 1), which in turn informed the script for the interview study. Detailed methods and results from this qualitative work have already been published [10].

\subsection{Identifying Initial Attributes}

The research team built upon our previous qualitative work to develop the DCE instrument. To identify potential attributes for the DCE, we reviewed transcripts from the interview study to select key factors associated with consuming cannabis for symptom management, as articulated by cancer survivors. The key factors were selected based on the following criteria: survivors' articulated preferences from the interview study and whether the factors could be represented in each of the three TPB constructs. This assessment helped ensure the DCE design was based on both evidence and theory. The key factors identified at this stage formed the emergent long list of potential attributes for the DCE instrument.

\subsection{Reducing the Initial List of Attributes and Creating Levels}

A process of reducing and refining the initial attributes followed. Our goal at this stage was to reduce the long list of attributes to a manageable and meaningful number for respondents to appraise in a series of DCE choice sets and to produce quantitative evidence useful to policy makers. To this end, the relative value of each initial attribute was further assessed to determine whether it was sensitive to the Canadian context, was modifiable to produce levels and trade-offs, and was amenable to policy intervention. At least one attribute from each of the three TPB constructs would be retained to support the theoretical foundations of the DCE design. Although DCE design is not prescriptive about the number of attributes to be included in a choice set, most DCEs have between three and seven attributes and two to four levels to reduce the cognitive burden of the choice task and generate reliable valuation data [27-29].

\subsection{Think-Aloud Exercises with Debriefing Interviews}

We conducted think-aloud exercises to assess whether the selected DCE attributes and levels were meaningful and well-understood by respondents. Think-aloud exercises are used to help researchers understand how individuals grasp and respond to a given task by asking them to provide "onthe-spot" verbal feedback as they complete the task [26]. For this study, the task included introductory material and an initial preference survey of four choice sets. A debriefing interview followed the task completion.

We included cancer survivors and the lay public at this stage, since DCE attribute selection requires a good understanding of the target population's perspectives and experiences [21], and a lay audience is the intended population for the final DCE. Participants were recruited through BC Cancer's Patient Partners network (for patients) and participants from previous studies who had indicated a desire to be involved in subsequent research (for the general public). An email with information about the study was sent to potential participants. Each participant received a \$Can50 gift voucher.

We developed a script based on the findings from the literature search and interviews to support participants in 


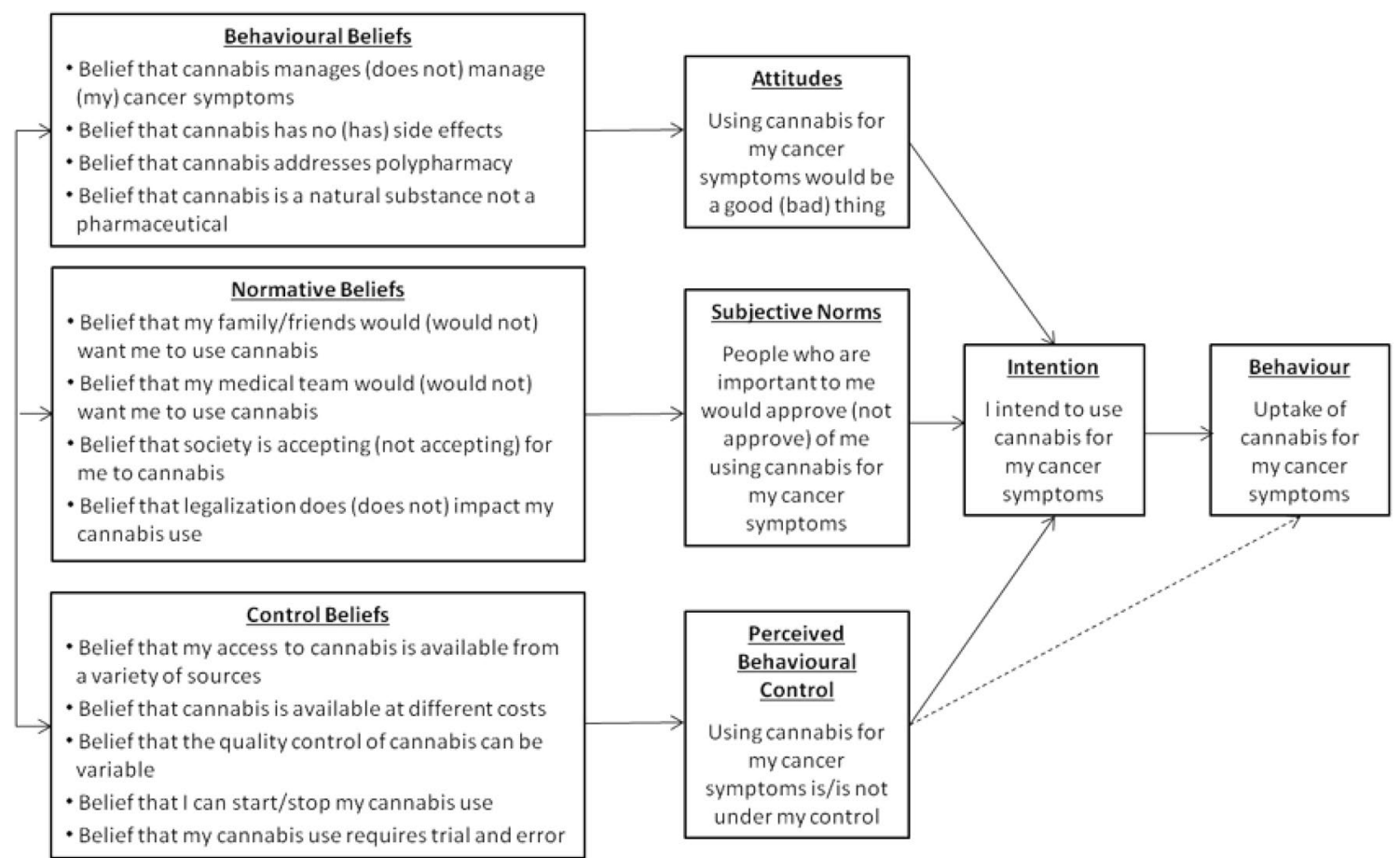

Fig. 1 Mapping findings from the literature review to the Theory of Planned Behaviour (from McTaggart-Cowan et al.) [10]

completing the think-aloud exercise. All exercises were held via Zoom, and the script was visible to participants and interviewer throughout the exercise. The script asked participants to imagine themselves as cancer survivors faced with the decision of taking cannabis to help treat their cancer-related symptoms. The script provided background information on cancer rates in Canada, the use of cannabis for medicinal and recreational purposes, its potential benefits in alleviating cancer symptoms, and consumption side effects (e.g., relaxation, euphoria, increased appetite, difficulty concentrating). It also guided the participant through a sample DCE choice set and explained the participant's role in verbalizing their thoughts while completing the four choice sets of the initial survey. The choice sets used in the think-aloud exercises were formulated by the research team. The presented choice sets encouraged the participants to consider choosing between the options. At this stage, it was not imperative for participants to complete experimentally designed choice sets, since the number of attributes and number of levels may alter after the completion of the think-aloud exercises.

Following the think-aloud exercise, each participant took part in a semistructured debriefing interview. These interviews provided a longer temporal frame than "on-thespot" think-alouds for participants to provide feedback on the choice task. During this interview, participants were asked for feedback on the clarity of the task, whether any attribute(s) anchored their decisions and why, and whether their decision-making processes changed over the course of the survey. All think-aloud exercises were audio recorded and reviewed independently by two members of the research team (SIN, HMC).

\section{Results}

\subsection{Identifying Initial Attributes}

From the interview study, we identified 12 factors associated with cannabis consumption for symptom management that were important to cancer survivors. These factors formed the long list of attributes eligible for the DCE design. The attributes were mapped onto the TPB constructs. Table 1 shows the mapping of the qualitative evidence from the interviews to the TPB constructs and the preliminary DCE attributes.

\subsection{Reducing the Initial List of Attributes and Creating Levels}

Of the 12 initial attributes identified in the previous stage, six were retained and further refined, and one was added. "My family's approval" and "my doctor's recommendation on medicating with cannabis" were retained as attributes, despite seeming impervious to intervention and modification. They were retained because several survivors spoke about the negative social norms (or stigma) often associated 
with cannabis consumption, and some oriented their decision to take (or forego) medicinal cannabis in relation to these perceived norms. Thus, the degree of family and/or physician approval-with "approval" and "recommendation" modified to "opinion" - of cannabis consumption reflected real-world trade-offs for survivors.

In our interview study, only cancer survivors who consumed cannabis referred to the cost of cannabis. However, we retained the attribute "my monthly out-of-pocket cost" to include willingness to pay as part of the overall assessment of perceived benefits. Cost is a factor inherent to decisions about medicating cancer symptoms with cannabis, since cannabis is not available free of charge in Canada. As such, the exclusion of cost would create an inaccurate representation of the decision-making scenario. Setting the appropriate levels for this attribute was challenging. If the levels were too low, it could result in nontrading of the cost attribute. The research team reviewed prices of cannabinoid products from online sources to ensure the lowest level was realistic. During the interview study, a cancer survivor referenced an annual cost of $\$$ Can11,000 for her medical cannabis, which allowed her to qualify for tax credits. This amount informed the maximum cost level of \$Can1000 for the "my monthly out-of-pocket cost" attribute in the think-aloud choice set.

The attribute "everyday activities" was added at this stage. The ability to perform everyday activities was added as an indirect measure of quality of life because functional abilities in activities of daily living are associated with the quality of life of patients with cancer [30]. Even though quality of life was not explicitly asked during the semistructured interviews, it was included as an attribute because nearly all participants discussed that medicating with cannabis could enable to them to perform their everyday activities. Table 2 describes further refinement of the initial attributes.

Table 3 shows the revised attributes and levels used to generate the DCE choice sets as well as their mapping to the TPB constructs. An initial preference survey of four choice sets, minus the TPB constructs, was generated by the research team to be used in the think-aloud exercises.

\subsection{Think-Aloud Exercises with Debriefing Interview}

We conducted ten think-aloud exercises, six with patient partners and four with members of the general public. One patient partner had not used cannabis as a treatment option, four had medicated their cancer symptoms with cannabis, and one did not disclose whether they used cannabis for their cancer symptoms. Two members of the public had previous experience with research and DCEs. The think-aloud exercises lasted 20-41 min (average $30 \mathrm{~min}$ ).

The DCE survey and background script were revised iteratively by SIN and HMC based on participants' feedback in the think-aloud exercises. For the first three think-aloud exercises with patient partners, participants read the background script, the interviewer explained the example DCE task and how to complete the survey, and participants then completed the survey. At this stage, grammatical errors and diction were corrected, instructions simplified, the order of presenting the information modified, and wording changed (e.g., "characteristics of cannabis" was replaced by "features of cannabis").

Most participants indicated difficulty understanding the meaning of the attributes "chance of side effects" and "everyday activities." "Side effects" seemed to be a subjective feature, with participants having their own definitions. For example, one participant identified "increased appetite" as a positive side effect of cannabis, whereas another identified it as negative. Accordingly, the wording was updated to "chance of unwanted side effects" to allow this variability in definitions. "Everyday activities" was often equated with "effectiveness of cannabis." To clarify the distinction between these two attributes, we simplified the instructions and explicitly defined each attribute as part of the background script. For the next seven think-aloud exercises, participants read the instructions themselves before completing the survey. If needed, the interviewer answered participants' questions and clarified the task. The interviewer (SIN) conducted all ten debriefing interviews.

The DCE survey and background script were further refined at this stage. The maximum cost level for the attribute "my monthly out-of-pocket cost" was lowered to $\$$ Can750 from \$Can1000 because the higher value tended to anchor some decisions, indicating participants' choices were overdetermined [17]. Participants collectively indicated that understanding the DCE choice task was challenging at first but became easier as they went through more questions and identified their priorities for decision making. Table 4 shows the final list of attributes and levels.

The lengthy background script was later incorporated into a 3-min explainer video for the DCE. Participants watched the video before undertaking the survey to help shorten the time required to complete the overall task and make the task more readily understood. Participants were also able to view the script text alongside the video. A copy of the video can be found in the electronic supplementary material.

Finally, we noticed during the interviews that personal values and stage of cancer treatment might impact participants' thought processes and decision making. Accordingly, demographic questions and questions regarding participants' experiences with cancer would be added to the DCE pilot study and the main study to further investigate their associations. 
Table 1 Initial 12 attributes, sample quotations from participants, and theory of planned behavior constructs

\begin{tabular}{|c|c|c|}
\hline TPB construct & Quotations from transcribed interviews with cancer survivors & Initial DCE attribute \\
\hline Behavioral & $\begin{array}{l}\text { "I've been kind of struggling with this whole - I realized how well [cannabis] works for sleeping } \\
\text { because of course the initial diagnosis was terribly emotional and draining." (ID8) } \\
\text { "[Cannabis] just helps me to think and focus and really try to understand where I'm going in life, } \\
\text { why this is happening to me ... . When I don't smoke weed sometimes I can get ... not depressed } \\
\text { but, you know, sad about some things, and weed helps to relax that." (ID31) }\end{array}$ & Effectiveness of cannabis \\
\hline Behavioral & $\begin{array}{l}\text { "I mean it was good for my nausea, it was good for sleeping, it was good for depression, anxiety. } \\
\text { The pain, I guess. I think it was good for joint pain as well." (ID27) } \\
\text { "[I]t has helped because of the ability to now sleep through the night again [and] ... help with } \\
\text { anxiety and depression, because I got rest. So, it actually kept me off antidepressants." (ID10) }\end{array}$ & $\begin{array}{l}\text { Management of cancer } \\
\text { symptoms }\end{array}$ \\
\hline Behavioral & $\begin{array}{l}\text { "I guess if there is any drug downside it can kind of make you drowsy a little bit, but at the same } \\
\text { time it makes me sleep better the night before. So it's a bit of a catch 22." (ID27) } \\
\text { "One, I don't like anything in my lungs and yesteryear it was always smoking it, okay? And that } \\
\text { was one thing. And then the other reason [for not medicating symptoms with cannabis] was that } \\
\text { I heard that people had the munchies with it and I didn't want to keep eating because of that." } \\
\text { (ID24) }\end{array}$ & Side effects of cannabis \\
\hline Behavioral & $\begin{array}{l}\text { "I actually refrained from using some of my chemotherapy pills in exchange for marijuana, like the } \\
\text { nausea pills." (ID27) } \\
\text { "I really don't like taking medicine, so I really like to find an alternative. And I did research on } \\
\text { [cannabis] and I didn't see where there was that many side effects. But as you read the medica- } \\
\text { tion that I'm on, there was a lot of side effects." (ID1) }\end{array}$ & $\begin{array}{l}\text { Polypharmacy (manage- } \\
\text { ment of medicines) }\end{array}$ \\
\hline Normative & $\begin{array}{l}\text { "I've spent far too many years worrying about what everybody else thought of me, you know, only } \\
\text { to get to this point in my life and say, I really don't give a damn. It's all about me now." (ID9) } \\
\text { "[F]or example, my mom, which is the older generation ... it was very like, 'Oh my God, [...] how } \\
\text { are you going to deal with - you know, you're going to be high all the time."” (ID10) } \\
\text { "And a lot of it is still a secret because I have children, and I'm not too sure how they would react." } \\
\text { (ID6) }\end{array}$ & $\begin{array}{l}\text { My family's approval of } \\
\text { my medicating with } \\
\text { cannabis }\end{array}$ \\
\hline Normative & $\begin{array}{l}\text { "I've had a number of oncologists over the course of my treatment, and no-one has ever raised it } \\
\text { as something to even think about, so I kind of wonder whether the medical professional[s] really } \\
\text { look at it as being a good alternative." (ID9) } \\
\text { "Both my family doctor and the specialists that I've seen have advised that there are people who } \\
\text { use cannabis, that there are people that benefit from it, and there are people that don't benefit } \\
\text { from it. So, they say it will be a conscious decision on my own part if I wanted to do it, and if I } \\
\text { wanted to and I needed their help, they would help me with it." (ID15) } \\
\text { "My own personal physician that I've had for } 25 \text { years said, 'If you're using [cannabis] then you'd } \\
\text { better find a new doctor because I won't see you anymore.' So I've had to hide it from him } \\
\text { because otherwise he's kicking me out the door." (ID14) }\end{array}$ & $\begin{array}{l}\text { My doctor's recommenda- } \\
\text { tion on medicating with } \\
\text { cannabis }\end{array}$ \\
\hline Normative & $\begin{array}{l}\text { "I was hoping that the specialist could give me, you know, like a prescription with like a dose that } \\
\text { has been shown to alleviate symptoms or things like that." (ID21) }\end{array}$ & $\begin{array}{l}\text { Receipt of medical can- } \\
\text { nabis prescription or } \\
\text { referral }\end{array}$ \\
\hline Normative & $\begin{array}{l}\text { "Well, it gives me a chance to remove the illegal, you could get into trouble, you could go to jail } \\
\text { stigma attached to it. So that's really important for me because of my dad being a police officer } \\
\text { and me being a teacher and all of the things that are associated with that and a role model and } \\
\text { things like that." (ID24) } \\
\text { "The legalization [of cannabis] didn't [change my willingness to medicate with it]. My work ... } \\
\text { has taken me overseas and into the States. And I do not want to wind up going to a border cross- } \\
\text { ing and being asked if I use cannabis. I don't want to have to say yes." (ID15) }\end{array}$ & Legalization of cannabis \\
\hline Control & $\begin{array}{l}\text { "The cost for a cancer patient to buy medical marijuana through one of the legal providers is astro- } \\
\text { nomical and extremely unrealistic for anybody to go through." (ID27) } \\
\text { "Because even now with the legalization, the one legal store here and the two [other] ones, I can } \\
\text { buy it from my guy at a hell of a lot less than what those stores are asking for their price." (ID7) } \\
\text { "My tax last year, I was [paying] \$11K in a year. [...] And that was only medicinal." (ID16) }\end{array}$ & $\begin{array}{l}\text { My monthly out-of-pocket } \\
\text { cost }\end{array}$ \\
\hline Control & $\begin{array}{l}\text { "So, to go see the [cannabis] specialist at the clinic, I needed to have a referral from my oncologist. } \\
\text { [...] So when I asked her, she willingly signed the paper. She said, 'For sure, there's no harm in } \\
\text { that."' (ID21) } \\
\text { "[My family doctor] did not prescribe [cannabis], but she was very supportive but couldn't facili- } \\
\text { tate it, fine. Cancer doctor was also very open and very supportive but ... she doesn't deal with } \\
\text { any of the prescription there and does not agree with opiate use at this time." (ID16) }\end{array}$ & Access to cannabis \\
\hline
\end{tabular}


Table 1 (continued)

\begin{tabular}{lll}
\hline TPB construct & Quotations from transcribed interviews with cancer survivors & Initial DCE attribute \\
\hline Control & "I was experimenting with the tinctures before, and I wasn't sure how much I need to take." (ID8) & Cannabis dosage \\
& "I wonder what would be the ideal amount if somebody knew a lot about this topic and was like, \\
& 'Here's the ideal amount you should be having.' You know, 'You should be taking it once a \\
& week' or like, 'once a month' or 'You should be taking this one that's this percentage of THC \\
& and this percentage of CBD.' Like if somebody knew that information ... that would be helpful." \\
& (ID32) \\
"I went on a couple international trips, so of course I didn't travel with any cannabis, and I had no & Ability to stop medicating \\
Control & with cannabis \\
& "During treatment, probably [used edibles] only the first few days, three to four days after my treat- \\
& ment, because that was when my symptoms were the worst .... And then I would stop using it." \\
& (ID23) & \\
\hline
\end{tabular}

$C B D$ cannabidiol, $D C E$ discrete choice experiment, $T H C$ tetrahydrocannabinol, $T P B$ theory of planned behavior

\section{Discussion}

The article reports on the formative qualitative research undertaken to design a DCE on cancer survivors' reasons for selecting (or not) cannabis for symptom management. Our objective for this article was twofold: to outline carefully the methods used to collect qualitative preference evidence to inform the DCE design and, in doing so, adhere to recent guidelines for better reporting of qualitative work associated with attribute development [18]. From our previous qualitative work involving a literature search and interview study, we identified a long list of potential attributes affecting survivors' decisions to medicate their symptoms with cannabis; the list was revised by the research team and further refined through think-aloud exercises to form the final attributes and levels. The TPB provided a theoretical framework for conceptualizing preferences regarding therapeutic cannabis use. Overall, this approach provided robust qualitative evidence for developing a preference-based instrument that would be realistic, policy relevant, and acceptable to respondents.

A key contribution of qualitative work to attribute development is to contextualize stakeholders' preferences and support person-centered care [17, 22, 31]. The legalization of recreational cannabis consumption in Canada, together with increased consumption post legalization, suggested growing public acceptability of cannabis use amongst Canadians. However, it was clear from the prior interview study that stigmatization remains a concern. Many cancer survivors held normative beliefs regarding the need for approval from family and friends when deciding whether to manage their cancer symptoms with cannabis. Some chose not to disclose their behavior to others for fear of social censure, including, at times, from their healthcare providers. Thus, the decision to consume cannabis continued to be viewed as a meaningful social action involving real-world trade-offs for Canadian cancer survivors. These findings supported our decision to include family and physician opinion as attributes and confirmed the importance of incorporating preferences beyond immediate health outcomes in DCE instruments [32].

Participants' willingness to pay was also context sensitive, and estimating cost levels for the "my monthly outof-pocket cost" attribute presented challenges for the DCE design. These challenges may be attributed to the difficulty of defining cost and its appropriate levels in the context of publicly funded healthcare systems such as in Canada [32]. Including a monthly out-of-pocket expense in healthcare decision making may have appeared unusual to respondents, even though medicinal cannabis is not available free of charge in Canada. Indeed, results from the think-aloud exercises showed that the cost attribute tended to distract participants and anchor their decisions. Moreover, the plethora of medicinal cannabis products available on the market made it difficult for the research team to estimate a realistic range of cost values. Although we modified the cost valuations during the qualitative process, planned pilot work with members of the Canadian public (approximately 200 respondents) will help further gauge the sensitivity of a willingness-to-pay attribute in the Canadian context and provide additional opportunity for attribute level refinement.

There are some limitations to the findings from this study. In qualitative research such as this, generalizations cannot be made based on representativeness. Recruitment for the think-aloud exercises relied on convenience sampling, which can lead to non-coverage bias. Because all qualitative work was conducted in English, we may have missed important perspectives from non-English-speaking survivors. Participants' status as cancer survivors was self-reported. We did not ask for medical records to verify their treatment status so were unable to delineate differences regarding risks and benefits of individuals undergoing active treatment versus those who have completed treatment. Finally, the qualitative work 
Table 2 Further refinement of initial attributes

\begin{tabular}{|c|c|c|}
\hline Initial attribute & Modification and reason & Revised attribute(s) (if applicable) \\
\hline Management of cancer symptoms & Combined with "effectiveness of cannabis" & Effectiveness of cannabis \\
\hline Polypharmacy & $\begin{array}{l}\text { Removed, because the content captured under this } \\
\text { concept was too diffuse }\end{array}$ & NA \\
\hline Dosage & $\begin{array}{l}\text { Captured under "access to cannabis" and "my doc- } \\
\text { tor's opinion about cannabis" }\end{array}$ & $\begin{array}{l}\text { Access to cannabis; my doctor's opinion about } \\
\text { cannabis }\end{array}$ \\
\hline Receipt of medical cannabis prescription & $\begin{array}{l}\text { Captured under "access to cannabis" and "my doc- } \\
\text { tor's recommendation on medicating with can- } \\
\text { nabis"; "my doctor's recommendation" changed } \\
\text { to "my doctor's opinion" }\end{array}$ & $\begin{array}{l}\text { Access to cannabis; my doctor's opinion about } \\
\text { cannabis }\end{array}$ \\
\hline Ability to stop medicating with cannabis & Captured under "side effects of cannabis" & Chance of side effects \\
\hline Legalization of cannabis & $\begin{array}{l}\text { Removed, since it describes the current state of } \\
\text { legislation in Canada }\end{array}$ & NA \\
\hline My monthly out-of-pocket cost & $\begin{array}{l}\text { Although only some cancer survivors referred to } \\
\text { the cost of cannabis, a willingness-to-pay attrib- } \\
\text { ute was retained to provide an accurate represen- } \\
\text { tation of the decision-making scenario }\end{array}$ & My monthly out-of-pocket cost \\
\hline NA & $\begin{array}{l}\text { The ability to perform everyday activities was } \\
\text { added as an indirect measure of quality of life. } \\
\text { It was not explicitly asked during the semistruc- } \\
\text { tured interviews, but most participants believed } \\
\text { that medicating with cannabis could enable to } \\
\text { them to perform their everyday activities }\end{array}$ & Everyday activities \\
\hline
\end{tabular}

NA not applicable

Table 3 Revised list of attributes, levels, and related TPB constructs

\begin{tabular}{lll}
\hline TPB & Attribute & Level \\
\hline Behavioral & Effectiveness of cannabis & Cancer symptoms are managed all the time \\
& & Cancer symptoms are managed most of the time \\
Behavioral & Everyday activities & Cancer symptoms are managed some of the time \\
& & Performed all the time \\
& & Performed most of the time \\
Behavioral & Chance of side effects & Performed some of the time \\
& & High \\
& & Moderate \\
Normative & Opinions of my family and friends & Low \\
& about cannabis & Supports my cannabis medication \\
& & Somewhat supports my cannabis medication \\
Normative & My doctor's opinions about cannabis & Does not support my cannabis medication \\
& & Supports my cannabis medication \\
& & Somewhat supports my cannabis medication \\
Control & Access to cannabis & Does not support my cannabis medication \\
& & Prescription obtained from my doctor \\
& & Prescription obtained from a cannabis clinic \\
& & Obtained from a neighborhood dispensary \\
& & Obtained from another source \\
& & $\$ 50$ \\
& My monthly out-of-pocket cost & $\$ 100$ \\
& & $\$ 250$ \\
& &
\end{tabular}

Costs are presented in Canadian dollars

$T B P$ theory of planned behavior 
Table 4 Final attributes and levels

\begin{tabular}{lll}
\hline TPB & Attribute & Level \\
\hline Behavioral & Effectiveness of cannabis & Cancer symptoms are managed all the time \\
& & Cancer symptoms are managed most of the time \\
Behavioral & Everyday activities & Cancer symptoms are managed some of the time \\
& & Performed all the time \\
& & Performed most of the time \\
Behavioral & Chance of unwanted side effects & Performed some of the time \\
& & High \\
& & Moderate \\
Normative & Opinions of my family and friends & Low \\
& about cannabis & Supports my cannabis medication \\
& & Somewhat supports my cannabis medication \\
Normative & My doctor's opinions about cannabis & Does not support my cannabis medication \\
& & Supports my cannabis medication \\
& & Somewhat supports my cannabis medication \\
Control & Access to cannabis & Does not support my cannabis medication \\
& & Prescription obtained from my doctor \\
& & Prescription obtained from a cannabis clinic \\
& & Obtained from a neighborhood dispensary \\
& & Obtained from another source \\
& & $\$ 50$ \\
& & $\$ 100$ \\
& & $\$ 250$ \\
& &
\end{tabular}

Costs are presented in Canadian dollars

$T B P$ theory of planned behavior was conducted in 2019-2021, shortly after the 2018 legalization of recreational cannabis use in Canada. Participants' perceptions of the impact of legalization on medicinal cannabis use may not have easily distinguished between these contexts. Furthermore, participants may have become more informed regarding alternative modes of cannabis delivery post legalization, so mode of delivery may not have strongly factored into individuals' decision-making processes. However, this warrants further investigation.

\section{Conclusion}

This qualitative study outlines the theory-informed, multistage methods used to collect preference evidence to inform a DCE quantitative survey. In so doing, it contributes to transparent reporting of qualitative work in DCE design. It also highlights the value of collecting evidence that is sensitive to the perspectives of patients and the specific socio-medical context in which a healthcare good or service-in this case, the use of cannabis for therapeutic purposes-is considered. In jurisdictions such as Canada, where recreational cannabis consumption was recently legalized, understanding what affects cancer survivors' decisions to use cannabis for symptom relief with or without medical guidance can help inform health policies designed to support shared decision making between cancer survivors and their physicians.

Supplementary Information The online version contains supplementary material available at https://doi.org/10.1007/s40271-021-00567-3.

\section{Declarations}

Funding The study was funded by the Canadian Centre for Applied Research in Cancer Control (ARCC). ARCC is funded by the Canadian Cancer Research Institute (Grant \#2020-706936).

Conflicts of interest $\mathrm{CB}, \mathrm{SIN}, \mathrm{AR}$, and HMC have no conflicts of interest that are directly relevant to the content of this article.

Availability of data and material De-identified data are available from the corresponding author upon reasonable request.

Code availability Not applicable.

Ethics approval The study protocol was approved by the BC Cancer Research Ethics Board (H19-01489).

Consent to participate All participants in this study provided informed consent. 
Consent for publication Not applicable.

Author contributions All authors contributed to the study design and analyzed the data. SIN and HMC prepared the materials, SIN collected the data, and HMC supervised the study. CB wrote the first draft of the manuscript; all authors commented on subsequent versions and read and approved the final manuscript.

Open Access This article is licensed under a Creative Commons Attribution-NonCommercial 4.0 International License, which permits any non-commercial use, sharing, adaptation, distribution and reproduction in any medium or format, as long as you give appropriate credit to the original author(s) and the source, provide a link to the Creative Commons licence, and indicate if changes were made. The images or other third party material in this article are included in the article's Creative Commons licence, unless indicated otherwise in a credit line to the material. If material is not included in the article's Creative Commons licence and your intended use is not permitted by statutory regulation or exceeds the permitted use, you will need to obtain permission directly from the copyright holder. To view a copy of this licence, visit http://creativecommons.org/licenses/by-nc/4.0/.

\section{References}

1. Cannabis legalization and regulation. Ottawa: Government of Canada, Department of Justice; 2018.

2. The health effects of cannabis and cannabinoids: the current state of evidence and recommendations for research. National Academies of Science, Engineering and Medicine; 2017.

3. Schlag AK, O'Sullivan SE, Zafar RR, Nutt DJ. Current controversies in medical cannabis: Recent developments in human clinical applications and potential therapeutics. Neuropharmacology. 2021;191:108586.

4. Karanges EA, Suraev A, Elias N, Manocha R, McGregor IS. Knowledge and attitudes of Australian general practitioners towards medicinal cannabis: a cross-sectional survey. BMJ Open. 2018;8(7):e022101

5. McLennan A, Kerba M, Subnis U, Campbell T, Carlson LE. Health care provider preferences for, and barriers to, cannabis use in cancer care. Curr Oncol. 2020;27(2):e199-205 (PubMed PMID: 32489269. Epub 2020/05/01. eng).

6. National cannabis survey, fourth quarter 2018. In: Canada S, editor. Ottawa: Government of Canada; 2018.

7. National cannabis survey, third quarter 2019. In: Canada S, editor. Government of Canada; 2019.

8. Satterlund TD, Lee JP, Moore RS. Stigma among California's Medical Marijuana Patients. J Psychoact Drugs. 2015;47(1):10-7.

9. Bottorff JL, Bissell LJL, Balneaves LG, Oliffe JL, Capler NR, Buxton J. Perceptions of cannabis as a stigmatized medicine: a qualitative descriptive study. Harm Reduct J. 2013;10(1):2.

10. McTaggart-Cowan H, Bentley C, Raymakers A, Metcalfe R, Hawley P, Peacock S. Understanding cancer survivors' reasons to medicate with cannabis: a qualitative study based on the theory of planned behavior. Cancer Med. 2021;10(1):396-404.

11. Turgeman I, Bar-Sela G. Cannabis for cancer-illusion or the tip of an iceberg: a review of the evidence for the use of Cannabis and synthetic cannabinoids in oncology. Expert Opin Investig Drugs. 2019;28(3):285-96.

12. Blake A, Wan BA, Malek L, DeAngelis C, Diaz P, Lao N, et al. A selective review of medical cannabis in cancer pain management. Ann Palliat Med. 2017;6(Suppl 2):S215-22 (PubMed PMID: 28866904. Epub 2017/09/05. eng).
13. Mullan F. Seasons of survival: reflections of a physician with cancer. N Engl J Med. 1985;313(4):270-3.

14. Ryan M. Discrete choice experiments in health care. BMJ (Clinical research ed). 2004;328(7436):360-1 (PubMed PMID: 14962852. eng)

15. Ryan M, Farrar S. Using conjoint analysis to elicit preferences for health care. BMJ. 2000;320(7248):1530-3 (PubMed PMID: 10834905. Pubmed Central PMCID: PMC1118112. Epub 2000/06/02. eng).

16. Trapero-Bertran M, Rodríguez-Martín B, López-Bastida J. What attributes should be included in a discrete choice experiment related to health technologies? A systematic literature review. PLoS ONE. 2019;14(7):e0219905 (PubMed PMID: 31318926. Pubmed Central PMCID: PMC6639002. Epub 2019/07/19. eng).

17. Coast J, Al-Janabi H, Sutton EJ, Horrocks SA, Vosper AJ, Swancutt DR, et al. Using qualitative methods for attribute development for discrete choice experiments: issues and recommendations. Health Econ. 2012;21(6):730-41 (PubMed PMID: 21557381. Epub 2011/05/11. eng).

18. Hollin IL, Craig BM, Coast J, Beusterien K, Vass C, DiSantostefano $\mathrm{R}$, et al. Reporting formative qualitative research to support the development of quantitative preference study protocols and corresponding survey instruments: guidelines for authors and reviewers. Patient. 2020;13(1):121-36 (PubMed PMID: 31840215. Epub 2019/12/17. eng).

19. Horrocks CJaS. Developing attributes and levels for discrete choice experiments using qualitative methods. J Health Serv Res Policy. 2007;12(1):25-30 (PubMed PMID: 17244394).

20. Kløjgaard ME, Bech M, Søgaard R. Designing a stated choice experiment: the value of a qualitative process. J Choice Model. 2012;5(2):1-18.

21. Vass C, Rigby D, Payne K. The role of qualitative research methods in discrete choice experiments. Med Decis Mak. 2017;37(3):298-313 (PubMed PMID: 28061040. Pubmed Central PMCID: PMC5367554. Epub 2017/01/07. eng).

22. Abiiro GA, Leppert G, Mbera GB, Robyn PJ, De Allegri M. Developing attributes and attribute-levels for a discrete choice experiment on micro health insurance in rural Malawi. BMC Health Serv Res. 2014;14(1):235.

23. Mangham LJ, Hanson K, McPake B. How to do (or not to do)... Designing a discrete choice experiment for application in a lowincome country. Health Policy Plan. 2009;24(2):151-8 (PubMed PMID: 19112071. Epub 2008/12/30. eng).

24. Ajzen I. The theory of planned behavior. Org Behav Human Decis Process. 1991;50(2):179-211.

25. Ajzen I, Fishbein M. The prediction of behavioral intentions in a choice situation. J Exp Soc Psychol. 1969;5(4):400-16.

26. Ericsson KA, Simon HA. Protocol analysis: verbal reports as data. Cambridge: The MIT Press; 1984. p. 426.

27. Bridges JF, Hauber AB, Marshall D, Lloyd A, Prosser LA, Regier DA, et al. Conjoint analysis applications in health-a checklist: a report of the ISPOR Good Research Practices for Conjoint Analysis Task Force. Value Health. 2011;14(4):403-13 (PubMed PMID: 21669364. Epub 2011/06/15. eng).

28. Marshall D, Bridges JFP, Hauber B, Cameron R, Donnalley L, Fyie $\mathrm{K}$, et al. Conjoint analysis applications in health-how are studies being designed and reported? The Patient Patient-Cent Outcomes Res. 2010;3(4):249-56.

29. Reed Johnson F, Lancsar E, Marshall D, Kilambi V, Mühlbacher A, Regier DA, et al. Constructing experimental designs for discrete-choice experiments: report of the ISPOR Conjoint Analysis Experimental Design Good Research Practices Task Force. Value Health. 2013;16(1):3-13 (PubMed PMID: 23337210. Epub 2013/01/23. eng). 
30. Brekke MF, la Cour K, Brandt Å, Peoples H, Wæhrens EE. The Association between ADL ability and quality of life among people with advanced cancer. Occup Therapy Int. 2019 2019; p. 2629673.

31. dosReis S, Castillo WC, Ross M, Fitz-Randolph M, Vaughn-Lee A, Butler B. Attribute development using continuous stakeholder engagement to prioritize treatment decisions: a framework for patient-centered research. Value Health. 2016;19(6):758-66 (PubMed PMID: 27712703. Epub 2016/10/08. eng).

32. Ryan M. Using conjoint analysis to take account of patient preferences and go beyond health outcomes: an application to in vitro fertilisation. Soc Sci Med. 1999;48(4):535-46. 